\title{
IDENTIDADE, NAÇÃO E TERRITÓRIO NA ESCRITA DOS INTELECTUAIS MAPUCHES*
}

\author{
Claudia Zapata Silva \\ Universidad de Chile
}

\begin{abstract}
RESUMO
Este artigo tem por objetivo dar conta de um novo sujeito indígena, surgido na segunda metade do século XX: o intelectual indígena contemporâneo, formado em instituições de educação superior e que constrói discursos e representações a partir de uma disciplina do conhecimento (História, Sociologia, Literatura, Antropologia, entre outras). Abordarse-á o caso particular dos intelectuais mapuches na década de noventa, a partir de uma perspectiva de análise que os considera como autores e como atores de contornos próprios no interior do que, na atualidade, se conhece como Movimento Mapuche.
\end{abstract}

PALAVRAS - CHAVE

Intelectual indígena. Identidade. Nação. Texto.

\section{INTRODUÇÃO}

Os intelectuais indígenas surgem da modernização latino-americana, principalmente daqueles projetos que se colocaram em marcha durante as primeiras décadas do século XX e cujo propósito foi a integração social e simbólica da nação. Foi o momento em que se produziu a ampliação do Estado, de suas bases cidadãs e o acesso paulatino à educação dos setores subordinados (os pobres, as mulheres e os indígenas). Este tipo de modernização trouxe consigo mudanças de grande envergadura para os grupos indígenas, entre elas a migração, a diversificação social e o acesso aos níveis superiores de educação que, apesar de ser tardia e ainda excludente, permitiu a configuração de um segmento novo, integrado por profissionais e intelectuais. ${ }^{1}$ Este processo permite rastrear o surgimento de um ator recente: os intelectuais indígenas, definidos pelo compromisso político que sustentam com suas culturas de origem, mas cujo trabalho intelectual é desenvolvido no interior da sociedade moderna. O reconhecimento que fazem esses intelectuais de sua trajetória social e de sua extração indígena configura um lugar de enunciação no qual sua produção fica unida a um

\footnotetext{
* Este artigo foi publicado em espanhol, numa versão ampliada, na Revista Mexicana de Sociología, v. 68, n. 3, jul.-set. 2006.

${ }^{1}$ CHONG. Mitos nacionalistas e identidades étnicas, p. 36.
} 
projeto político de reivindicação étnica. Isto é o que distingue esses intelectuais daqueles indígenas que, em décadas anteriores ou mesmo no presente, tiveram acesso à educação superior, mas cuja opção de vida não se encontra determinada por este compromisso.

No caso mapuche, ainda que a existência de profissionais e intelectuais deste tipo não constitua um fenômeno novo, hoje acaba sendo muito mais visível. No caso específico dos intelectuais, são vários os motivos deste maior delineamento público, entre eles, uma produção escrita abundante e sistemática, sua circulação por meios eletrônicos e, sobretudo, pelo momento crítico que atravessa hoje a relação entre mapuches e o Estado chileno. O propósito deste artigo é realizar uma aproximação do pensamento desses intelectuais por meio da sua produção escrita, sustentando que constitui uma parte importante do que, atualmente, se denomina Conflito Mapuche ou, de maneira mais ampla, Movimento Mapuche.

Com o objetivo de enquadrar historicamente a escrita desses intelectuais, é necessário deter-se na etapa mais contemporânea do Movimento Mapuche, aquela que se inicia em 1978 com a oposição de alguns setores da sociedade mapuche à ditadura militar. Naquele ano, o governo de facto promulgou um decreto que negava a existência da população indígena no Chile (D. L. 2.568), que foi qualificado de etnocida pelas organizações daquele momento. A partir desse marco histórico, sucederam distintos ciclos: o do retorno à democracia, onde se alcançou um relativo consenso sobre a necessidade de reconhecer a existência da diversidade cultural no Chile, processo que concluiu com a aprovação unânime da Lei Indígena, em 1993, e o ciclo atual que corresponde à ruptura desse consenso, pelo menos no que diz respeito aos mapuches. Entre eles, existe uma intelectualidade potente de alta formação acadêmica, cuja produção permite problematizar o vínculo entre intelectuais e movimentos sociais, pois ainda que a relação com as organizações exista (sem ser necessariamente uma militância), o que sobressai é a distância que se estabelece com elas, determinando uma relação na qual o indivíduo não se dissolve no coletivo, apesar de que o nós mapuche predomina como forma de enunciação. Esta distância é crítica, mas também é geográfica, pois muitos desses intelectuais se assumem como parte da "diáspora mapuche" no Chile ou no estrangeiro, situação que requer um tratamento específico. ${ }^{2}$

O que aqui interessa é calibrar a importância desses intelectuais mapuches na articulação de discursos críticos, representações e memórias que transpassam os limites comunitários e de parentescos, dos quais se desprendem, por sua vez, reivindicações e demandas (daí a ênfase na "nação mapuche" como um dos pilares sobre os quais se sustenta esta discursividade). A organicidade de ditos intelectuais encontra, neste exercício discursivo, uma expressão melhor que em sua militância (a que também existe por certo). O ponto de partida é uma definição de intelectual indígena que está determinada por sua função política, por se assumir índio, por se representar como tal e

\footnotetext{
${ }^{2}$ A situação de diáspora é relevante na escrita dos intelectuais que assumem o pertencimento a um grupo social ou cultural subordinado, como o assinalou Edward Said em numerosos trabalhos. Neste caso dos intelectuais mapuches que se foram para o exílio durante a ditadura militar (1973-1990), ou aqueles que foram voluntariamente do país, este deslocamento é um fator que se deve considerar na cosntrução de uma nova subjetividade (a identidade étnica e a luta política a ela associada).
} 
por se apropriar de sua história pessoal e familiar com o propósito de construir um lugar de enunciação a partir do qual se faz política, constrói-se conhecimento e se elaboram leituras indígenas com o objetivo de acabar com a situação de domínio que estes continuam experimentando. Trata-se então de uma opção, ideológica, poderíamos dizer, que se coloca acima da localização cultural problemática desses intelectuais (a qual pode ser denominada de mestiça, a partir de certos conceitos de cultura). ${ }^{3}$

\section{Os INTELECTUAIS MAPUCHES: UMA APROXIMAÇÃO A SUA ESCRITA}

As identidades indígenas contemporâneas, especificamente aquelas que animam os movimentos indígenas na América Latina, têm como centro a questão da cultura, plataforma de sua ação política. Este entrelaçamento entre cultura e política se faz patente numa das principais reivindicações: aquela que postula a diferença como direito inalienável de coletivos que se autodenominam povos. Isso explica a ênfase dos movimentos e organizações no tema da diferença, em torno do qual se articula sua produção discursiva. Um dos desafios principais consiste em fundamentar esta diferença - tanto no passado quanto no presente - e colocá-la no centro de sua relação com o Outro, esforço que cruza a totalidade dos documentos que se produzem em distintas instâncias desses movimentos (comunicados oficiais de organizações e comunidades em conflito e também textos de intelectuais indígenas), os quais transitam por um circuito que, no caso do Chile, é restrito se comparado ao de países do continente, mas que têm, de todas as maneiras, um espaço interessante na Internet e nas publicações independentes.

Nesta dinâmica, adquire importância a figura do intelectual indígena, pela qualidade de seus argumentos e pela relação que estabelece entre estes e as reivindicações políticas. A partir do ponto de vista do intelectual, não se trata só de constatar a existência dessa diferença cultural, senão de fundamentá-la num relato verossímil, e dela se apropriar numa construção identitária que seja funcional a estas lutas numa época da história que parece mais receptiva a este tipo de demandas. É importante fazer esta distinção entre cultura e identidade, pois a diferença não explica por si só o surgimento de uma identidade positiva em torno da categoria de índio. Isto atualiza um velho problema proposto pelo marxismo e que trouxe de volta Gayatri Spivak em seu ensaio de 1988, "Pode o subalterno falar?", no qual sustenta que o trânsito do "em si" (neste caso a sociedade indígena e sua situação de subordinação) ao "para si" (a apropriação dela e a possibilidade de teorizá-la para revertê-la em luta política), não é espontâneo e que, pelo contrário, a figura do intelectual é fundamental para realizá-lo.

O interessante, a partir de minha perspectiva, é que esse esforço de diferenciação cultural com a sociedade chilena como um todo provém daqueles que participam menos daquela "base objetiva" que seria a cultura tradicional, pois falamos de sujeitos cuja experiência de vida não é necessariamente a que se retrata em sua escrita (a comunidade rural, a dimensão ritual, etc.), mas sim o que nela mesma se chega a qualificar como seu oposto: a cidade, a educação universitária, a vida acadêmica, as viagens dentro e

\footnotetext{
${ }^{3}$ Ver GRUZINSKI. El pensamiento mestizo, p. 32.
} 
fora do país, enfim, um trânsito por outros lugares a partir daqueles que constroem uma forma particular de identidade indígena. Em que fundamentam então a diferença e, sobretudo, sua própria diferença? É uma pergunta que guia a leitura desses textos.

\section{IDENTIDADES INDÍGENAS E GLOBALIZAÇÃO}

Não é um mistério que no Chile o predomínio radical do mercado tenha se realizado num contexto autoritário e, paradoxalmente, a partir do Estado, ocupado violentamente pelos setores conservadores em 1973. Sem maiores mudanças na economia, durante os anos noventa, vai configurar um sistema político que restabeleceu os vínculos do país com a comunidade internacional (ocidental), re-inserção que permite entender a incorporação do tema das minorias à agenda política. Assim, seja por convicção ou pelo anseio de estar combinado com um novo tipo de modernização, os governos democráticos identificaram dois setores para aqueles que dirigiram políticas específicas desde então: as mulheres e os indígenas.

Isto gerou processos de distinto tipo, não todos previstos pela lógica política oficial, entre eles, um tipo de mobilização social realizado a partir de posições identitárias que já não são clássicas (o que em seu momento se denominou Novos Movimentos Sociais), com demandas que entrelaçam os âmbitos da política e da cultura, muitas vezes com predomínio dessa última. Isto no faz mais que dar conta do aspecto problemático desta globalização, já que não é possível reduzir a dinâmica social ao frio cálculo dos poderes mundiais, nem sequer em um país como o Chile, onde o controle sobre a sociedade civil parece ser mais eficiente.

Sobre o tema específico das diferenças (culturais, sexuais e de gênero), costuma aparecer com freqüência uma visão otimista da globalização, porque estaria permitindo sua expressão pública. Não obstante, esta visão - que não é completamente errada deve ser contrastada com um fato igualmente ineludível: que as diferenças culturais são objeto de um ordenamento hierárquico no nível planetário, utilizado em proveito de poderes hegemônicos, tanto políticos quanto empresariais. Isso obriga a relativizar a idéia de que a globalização favorece o desenvolvimento da democracia pelas condições que ela estaria oferecendo, neste caso, à livre expressão da diferença. Toda esta arrumação tem conseqüências na questão da identidade, por fatores estruturais (a inegável decadência dos Estados nacionais), políticos (queda do bloco socialista e desgaste dos discursos anti-sistêmicos) e outros de ordem mais subjetiva, que se relacionam com os anteriores na medida em que nivelam o caminho para a expressão de outras opções identitárias.

Com relação às identidades indígenas, fala-se de etnogêneses para conceituar seus processos de construção, o que, no caso mapuche, torna-se problemático, porque não é possível totalizar o conjunto de sua população num conceito que se refere a uma invenção a partir de experiências recentes, pois a continuidade da resistência (não em suas formas, como se esclareceu anteriormente), da mobilização e, sobretudo, da percepção da diferença ${ }^{4}$ não é um fenômeno recente. Por sua vez, tão pouco se pode destacar um

\footnotetext{
${ }^{4}$ MONTECINO; FOERSTER. Organizaciones, líderes y contiendas mapuches (1900-1970).
} 
conceito que, em outras experiências, pode resultar útil, como o dos filhos de mapuches nascidos em Santiago. Considerando esta complexidade, é possível encontrar aqueles signos de época sinalizados no começo deste apartado, e que marcam fortemente a escrita desses intelectuais, entre eles, um que é de grande importância. Refiro-me a uma auto-inclusão cada vez mais pública da identidade mapuche num contexto que, por motivos diversos e contraditórios, é cada vez mais favorável para que ela aconteça. Esta identidade mapuche pode variar nos seus conteúdos, mas estas condições fazem com que, de todas as formas, a afirmação de um eu mapuche possa ser algo muito mais visível. Encontramos um exemplo na obra de Elicura Chihuailaf, que narra uma experiência de vida em que esta mudança não é minimizada diante da continuidade da identidade mapuche que, paralelamente, afirma:

Parece-me que houve um processo de amadurecimento, de questionamento, produto de todas as mudanças que houve em nível mundial. Eu acredito, diz Francisco Caquilpan Lincuante (Kakvlpagi: León atravesado; Linkvantv: Puerta de sol), que hoje em dia seja mais fácil assumir a identidade; isso não era fácil há uns quinze anos. Por exemplo, o que vivi em minha comunidade foi minha condição de ser mapuche, mas aqui na cidade me dei conta de que ser mapuche era ser discriminado. No entanto, hoje as crianças reconhecem sua identidade no colégio e a assumem sem grandes traumas e a defendem e a fundamentam. ${ }^{5}$

\section{TEXTOS, DISCURSOS E ESCRITA}

A produção intelectual do período aqui abordado tem como principal suporte a escrita, confirmando novamente a importância de uma tecnologia cuja funcionalidade política foi advertida desde cedo pelos mapuches. ${ }^{6} \mathrm{Na}$ atualidade, isso não se reduz a um uso instrumental, pois já faz parte da experiência de vida desses intelectuais. No entanto, este predomínio da escrita sobre a oralidade provoca neles tensões derivadas da identidade e do sujeito mapuche que se constrói nestes textos, onde se assume que a oralidade é inerente à cultura mapuche. Novamente, recorro a Elicura Chihuailaf, que resolve esta tensão estabelecendo vínculos entre a oralidade e a escrita - o que ele denomina oralitura - animado pela convicção de que a palavra escrita é importante para retratar parte da história mapuche, mas insuficiente para dar conta da "imensidade dessa memória..."

Seguramente por isso, hoje acredito que - com o esforço de muitas perguntas - vi o livro como algo dos "outros". Daí, talvez, meu profundo interesse em abordá-lo como leitor motivado em saber algo mais dessa outridade. Isto é, infiro, sempre o vi como algo que somente os outros podiam fazer. Porém, enfrentando a realidade desse texto que pretende investir na tarefa de falar de aspectos do pensamento e da luta de minha gente, como fazê-lo?: Escutando - dizem-me -, para que você escute, a Palavra dos mais sábios. ${ }^{8}$

\footnotetext{
${ }^{5}$ CHIHUAILAF. Recado confidencial a los chilenos, p. 179.

${ }^{6}$ MONTECINO; FOERSTER. Organizaciones, líderes y contiendas mapuches (1900-1970).

${ }^{7}$ CHIHUAILAF. Recado confidencial a los chilenos, p. 25.

${ }^{8}$ CHIHUAILAF. Recado confidencial a los chilenos, p. 23-24.
} 
Para outros intelectuais, mais radicais em suas posturas de diferenciação cultural, esta tensão adquire contornos dramáticos. É o caso de Marcos Valdés (Wekull) e Eduardo Curín, que tratam de superá-la com a idéia de que a escrita e a formação acadêmica pode (e deve) derivar num fazer teórico capaz de independizá-los da racionalidade ocidental, o que, em sua opinião, vem instalar outra dimensão na luta pela autonomia. Falando dos intelectuais indígenas em geral, o sociólogo sustenta:

Deve-se reconhecer que, na realidade, vem sendo gestada uma camada emergente de intelectuais indígenas que, em muitos casos ou na grande maioria, foram formados por uma racionalidade não indígena ou sob a influência de sua produção, mas, paradoxalmente, são reativos e contrários a suas premissas teóricas fundamentais. ${ }^{9}$

Outros, ao contrário, omitem este problema e insistem na associação nítida entre oralidade e cultura mapuche, oposta à de escrita e cultura ocidental. Tensões deste tipo proliferam na produção desses intelectuais pela construção identitária que se trata de comunicar com ela, a qual coloca o acento na diferença cultural com o winka. Aqui, jogam uma função importante conceitos como os de cosmovisão, universo cultural, matriz cultural, entre outros, providos pelas Ciências Sociais. São conceitos que se encadeiam com esta lógica de argumentação, o que não quer dizer que se trate somente de operações discursivas ou de textos que busquem um "efeito de verdade", pois no caso mapuche esses elementos distintos existem, certamente, transformados no processo de contato e subordinação.

Pode-se dizer que, em geral, essa é a intencionalidade que articula os textos. Ao falar dela, refiro-me ao ato consciente e a funcionalidade política dos argumentos que desenvolvem e que têm como ponto de partida suas próprias histórias de vida. Isso revela a dimensão mais instrumental da identidade étnica, mas não exclui aquela subjetiva e emotiva que toda identidade possui e que nestes textos aparece com muita força.

Uma forma de abordar esta escrita é introduzindo a distinção teórica e metodológica entre texto e discurso. Como sinaliza Grínor Rojo, ${ }^{10}$ texto é um conceito amplo que pode ter distintos suportes, sendo a escrita uma de suas possibilidades, daí que não seja redundante falar de texto escrito para distingui-lo do texto oral, musical, iconográfico ou plástico. Por sua vez, e nisto Rojo segue o trabalho pioneiro de Bakthin, texto não é equivalente a discurso, mas sim uma totalidade composta por vários discursos que estabelecem um tipo de relação entre eles, sendo que essa análise pode ser de colaboração ou conflito. Estes aportes da teoria crítica são pertinentes para esta análise, pois permitem um tratamento mais produtivo de uma escrita na qual habitam discursos de distinta procedência que colaboram neste objetivo de fundamentar a diferença cultural e os direitos políticos associados a ela. Refiro-me à Historiografia, às Ciências Sociais, ao ecologismo, ao Direito, ao multiculturalismo e ao feminismo, entre outros, dentro dos quais se realiza uma seleção de acordo com os objetivos traçados por cada um dos autores. Porém, também aparecem relações conflitivas entre esses discursos, às vezes evidentes numa primeira leitura e, em outras, ocultas por detrás da força da

\footnotetext{
${ }^{9}$ VALDÉS \& CURÍN. A los intelectuales; o, de cómo resulta necesario repensar la cuestión mapuche, p. 173.

${ }^{10}$ ROJO. Diez tesis sobre la crítica.
} 
reivindicação política, como aquela que se dá entre o discurso do particular (a cultura mapuche) e aqueles argumentos que respaldam suas demandas, sustentados sobre a base de uma linguagem moderna que lhes permite falar, entre outras coisas, de direitos, um tema relevante que abordarei na parte final deste artigo.

Em temos de enunciação, esses textos se caracterizam porque um eu mapuche aparece - o do autor -, ao que se impõe um nós mapuche que sinaliza um desejo de representatividade com respeito a esse coletivo maior que pode ser a "sociedade mapuche", o "povo mapuche”, com um claro predomínio desta última denominação. Trata-se de um nós problemático diante da diversidade atual da população mapuche e do seu histórico faccionalismo político, diante dos quais se impõe como um esforço de integração simbólica. Também são textos que exploram a História para abordar questões contingentes, fixando uma posição mapuche e respaldando as organizações e comunidade em conflito. Daí, a coexistência de tempos históricos na narração, por exemplo, o da longa duração com o da conjuntura política. A maioria são ensaios e artigos que seguem as normas disciplinares (citações de autoridade e o respaldo da informação), base a partir da qual tentam deslocamentos para elaborar este lugar próprio. Isso se adverte de maneira muito clara no campo da História, onde abundam as tentativas para construir uma periodização mapuche, esforço que cruza os trabalhos do historiador Pablo Marimán.

A partir de um olhar ao conjunto dos textos reunidos, encontramos um primeiro nível de coincidências em que se compartilham premissas fundamentais, como a existência da nação mapuche, de um modo de vida que lhe é próprio e seu direito à autonomia. Porém, isso não significa que constituam um campo de argumentação coerente. De fato, em temas como a nação, a identidade, a História e a relação com o Estado chileno, encontramos um segundo nível de dissidências, representadas numa gama de posições políticas que se poderiam classificar, num primeiro momento, de integristas até outras mais dialogantes. Em várias ocasiões isto é sinalizado diretamente pelos autores, que polemizam a partir de seus trabalhos com outros intelectuais mapuches. O corpus a partir do qual formulo estas hipóteses se encontra conformado por textos produzidos entre os anos 1993 e 2003, a maioria deles com data posterior aos acontecimentos de Lumaco, comunidade da IX ${ }^{\mathrm{a}}$ região, onde se iniciou o atual conflito, em outubro de 1997. São, ao todo, um total de trinta e três textos correspondentes a dezoito autores, que se encontram nas páginas web ou em publicações impressas. Sua leitura impõe várias categorias de análise, mas este trabalho se centrará em três delas que me parecem fundamentais: identidade, nação e território.

\section{O MUNDO MAPUCHE}

O conceito de mundo mapuche é o mais utilizado pelos intelectuais para representar uma cultura distinta que persiste no interior do Estado chileno. Partindo desta diferença, faz-se o retrato de uma cultura compacta, de limites definidos e visíveis. Essa é caracterizada por um exercício de diferenciação e oposição que pode ser com a cultura chilena ou mais amplamente com a cultura ocidental, antagonistas que também são claramente distinguíveis e harmônicas entre si, especialmente em seu afã de domínio sobre esse mundo mapuche. 
Estes textos se sustentam sobre uma estrutura de narração na qual se distingue o par nós/eles, em torno do qual giram argumentos que reforçam uma fronteira cultural e geográfica que tem como símbolo o rio Bío Bío. Isto configura relatos nos quais se reproduz um tipo de divisão que marcou a história deste povo, deixando sua marca na memória; uma fronteira que contém em si mesma a tentação de essencializar o mapuche. A mesma sorte sofrem seus antagonistas, também descritos a partir de traços culturais fixos que não permitem abordar a diversidade que existe em seu interior. É o que ocorre com a associação chileno-ocidental, pois em geral se fala de Estado chileno sem diferenças, ${ }^{11}$ com a exceção de Arauco Chihuailaf, ${ }^{12}$ que trata de estabelecer a diferença entre um Estado de tom oligárquico e a sociedade civil sobre a qual governou. ${ }^{13} \mathrm{Na}$ escrita de Marhiquewun, esta fronteira é a marca principal de uma memória que se articula em torno da dor da derrota:

[...] não quero dizer ou me opor a que os chilenos comemorem os seus heróis. Eles, da mesma forma que nós, têm todo direito do mundo de fazê-lo; o que me incomoda é que durante suas comemorações nos envolvam a nós, os mapuches, e nos exijam que celebremos junto deles nossa derrota, o que nos faz recordar do genocídio cometido durante a Pacificação da Araucania, que além do mais, com eles nos recordam nossa condição de povo subjugado. ${ }^{14}$

A tradição é o tema que primeiro aparece quando esses intelectuais desenvolvam o conceito de mundo mapuche, pois conteriam em seu estado mais genuíno aquelas práticas e lógicas culturais que justificam o traçado desta linha demarcatória no presente. Fala-se, assim, do idioma, dos ritos, das crenças, da oralidade e de uma outra lógica política. A escrita dos intelectuais mapuches trata de se conectar com essa tradição e de refleti-la; com esta finalidade se incorporam palavras em mapudungún, e se resgatam conceitos e elementos que permitem estabelecer oposições do tipo oralidade/escrita, horizontalidade/verticalidade, diversidade/homogeneidade, entre outras. Um exemplo, entre vários, é um trabalho de Marcos Valdés (Wekull) e Eduardo Curín, onde esta oposição alcança seu zênite.

Na cultura mapuche não existe a separação entre o homem e a natureza, como existe na modernidade, mencionando de uma maneira simples o problema. Aos mapuche não só nos distinguem os temas de fronteiras institucionais, mas também outros da mesma forma complexos, mas no âmbito da cotidianidade, por isso é tão difícil, no inconsciente coletivo mapuche, entregar nacionalidade mapuche a um não mapuche; o tema não é institucional, é, definitivamente, o caráter de mundos distintos, por isso é um eterno paradoxo o ser mapuche e chileno ao mesmo tempo. ${ }^{15}$

\footnotetext{
${ }^{11}$ MARIMÁN. Transición democrática en Chile.

${ }^{12}$ CHIHUAILAF. La ausencia de Chile en "Chile: el país que viene".

${ }^{13}$ Este autor destaca o processo de construção do Estado chileno, identificado como um projeto de setores sociais específicos (a oligarquia primeiramente), do qual foram excluídos não somente os mapuches, mas também os setores populares.

${ }^{14}$ MARHIQUEWUN. Mapuches acusados de antipatriotas por chilenos nacionalistas y racistas.

${ }^{15}$ VALDÉS (WEKULL); CURÍN. A los intelectuales; o, de cómo resulta necesario repensar la cuestión mapuche, p. 171.
} 
A História joga um papel central neste propósito de diferenciação, pois permite a articulação de uma memória profunda (aquela que transcende a memória geracional) e de uma identidade positiva em torno dela. O historiador Pablo Marimán é um dos autores que estabelece com maior lucidez esta relação entre história, identidade e presente. $\mathrm{Na}$ reflexão que consegue articular a disciplina na qual foi formado com seu compromisso político, sustenta que a história fornece identidade e que pensar no passado é um exercício produtivo. ${ }^{16}$ Com este fim, recorre-se ao passado, mas não a qualquer período, mas sim àquele que permita se orgulhar de pertencer a esse mundo mapuche e que forneça dignidade a um povo cujos membros devem adquirir a consciência de que nem sempre foram dominados. ${ }^{17}$ Assim, para Marimán, o passado é "[...] como uma grande onda marinha que deixa seus elementos para que com eles sigamos reinventando nosso mundo". ${ }^{18}$

No exercício de sua disciplina, Pablo Marimán propõe a elaboração de uma história mapuche que tenha como conseqüência uma reescrita da história (oficial) chilena. Em "Elementos de história mapuche" (1996), ensaia esta reescrita a partir dos eixos principais: o primeiro deles é um tipo de narração desenvolvida em primeira pessoa, que permite ao autor se assumir como parte envolvida, o que distancia Marimán e a maioria dos intelectuais de que estamos tratando desse estilo objetivista (na terceira pessoa), considerado o mais apropriado para esta disciplina e demais Ciências Sociais; o segundo propõe a seguinte periodização: I. Independência política (desenvolvimento econômico e expansão territorial; Época de mudanças; Ocaso da vida independente); e II. Dominação e dependência (A História Contemporânea Mapuche; Movimento Mapuche e relações com o Estado; Um novo componente social: o mapuche urbano). Com esta periodização, Marimán instala uma posição que lhe permite reverter aquela relação que historicamente situou os mapuches como um sujeito narrado por outros.

Em termos de temporalidade, olhares como esses costumam esquivar o presente, ou desvalorizá-lo politicamente por ser sinônimo de domínio e subjugação. Assim, a valorização daquele passado, em que a cultura era livre e autêntica, opõe-se à inconformidade com um presente de relação obrigada com o Estado chileno. Esta percepção os leva a tomar distância do movimento mapuche que se desenvolveu a partir de 1910, e a olhar com receio as distintas estratégias de integração que propuseram as organizações desse período. Encontramos um exemplo desta crítica num artigo de José Marimán.

Ser Chileno representou, e ainda representa para alguns mapuche, inserir-se num marco civilizatório visto como superior. É por esta razão que as primeiras décadas do presente século viram emergir um discurso adulador das virtudes da cultura dominante, assim como o menosprezo da cultura própria. Algumas organizações mapuche farão fervorosos chamados para lutar contra a poligamia, o alcoolismo, a ignorância, a desvantagem técnica

\footnotetext{
${ }^{16}$ MARIMÁN. Gobierno y territorio en la independencia mapuche.

${ }^{17}$ É interesante a coincidência desta reflexão com a de alguns pensadores anticolonialistas do terceiro mundo, desenvolvida entre os anos cinqüenta e sessenta, para quem a exploração no passado da nãoopressão é um exercício que fornece dignidade aos colonizados, ao mesmo tempo em que constitui a forma mais eficiente de negar a inferioridade inculcada pelos colonizadores. Estou pensando em intelectuais como o poeta Aimè Cesaore (Discurso sobre o colonialismo, 1950) e o psiquiatra Frantz Fanon (Os condenados da terra, 1961), ambos da Martinica, colônia francesa no Caribe.

${ }^{18}$ MARIMÁN. Gobierno y territorio en la independencia mapuche, p. 25.
} 
e a favor da propriedade privada. "Deus" (cristão), e "progresso" (paradigma capitalista), será o lema da União Araucana, em 1916, e de seus militantes desejosos de se assimilarem. ${ }^{19}$

A partir desta perspectiva, toda relação, todo "cruzamento" com a sociedade chilena faz parte da história de usurpação que se abriu no final do século XIX, cujo custo mais alto foi a perda de sua autonomia. O questionamento de José Marimán sobre as organizações desse período se repete para as atuais, que têm em comum o fato de terem surgido da relação com os partidos políticos que ele denomina "estado-nacionais", categoria que não distingue entre os de esquerda e os de direita (J. Marimán, 1995). Neste argumento se sustenta a crítica que dirige ao Conselho de Todas as Terras e a seu líder Aucán Huilcamán, colocando em dúvida a representatividade cultural deste último por sua origem "alheia" ao mundo mapuche, em alusão a pugna partidária que o erigiu como líder.

Nesta memória, o presente - falamos do século XX - só representa usurpação, uma imagem que se retém para identificar uma relação final que completa o panorama; refiro-me àquela que estabelece a continuidade entre a história e as reivindicações atuais. Nisto radica o incômodo pelas declarações do historiador Sergio Villalobos à imprensa, em maio de 2000, pois, mais que o racismo intolerável de suas declarações, o que faz a tese do desaparecimento dos mapuches (via mestiçagem) é romper esta relação entre história, direitos ancestrais e os mapuches de hoje.

Em outro aspecto, a oposição de mundos tem conseqüência direta no sujeito mapuche que se configura nesses textos, vinculado estreitamente ao conjunto de práticas que compõem a tradição, e características que se consideram próprias dos mapuches e dos povos indígenas em geral. Isto resulta em descrições essencialistas de mapuches que, determinados por sua cultura, se oporiam ao racismo e à intolerância, que seriam protetores do meio ambiente, portadores de um sistema de vida sustentável com esse seu entorno natural e respeitosos da diversidade cultural. Ainda que nem todos os autores compartilhem de descrições tão idealizadas como a que faz Marhiquewun (1998b), esses elementos se encontram presentes em todos os trabalhos revisados, incluindo aqueles que se distanciam mais deste tipo de posições, como Elicura Chihuailaf (1999), que chega a sustentar que os indígenas são os guardiões mais legítimos da natureza.

Este sujeito mapuche e sua cultura adquirem sentidos e uma real materialização no território mapuche (atuais regióes VIII, IX e X). Isto faz com que fenômenos contemporâneos, como a migração para as cidades, não se articulem da melhor maneira com uma construção identitária que tem este território como um de seus pilares, porque nesta construção se exclui o espaço da cidade, especialmente se se trata de Santiago, que se localiza fora do território e simboliza o poder do Estado chileno. Assim, a migração é interpretada como uma conseqüência da dominação e como parte da derrota; um deslocamento que é sinônimo de perda e de aculturação, inclusive em autores que postulam o caráter dinâmico das identidades. Uma exceção interessante é um trabalho de Ramón Curivil, que fala do mapuche urbano como outra forma de ser mapuche, com um estilo de vida diferente, que para ele é uma opção válida e, mais ainda, que ser mapuche, na atualidade, implica a modificação dessa imagem tradicional e não poucas contradições.

${ }^{19}$ MARIMÁN. Movimiento mapuche y propuestas de autonomía en la década post dictadura. 
[...] já não somos o que foram nossos antepassados; não obstante, não quebramos com o passado. Somos o presente. Em nós se conjuga o moderno e o tradicional. O novo e o antigo. Somos um mapuche moderno: um pouco mais secular, mas crente; um pouco mais tradicional, mas moderno; chileno ou argentino, mas mapuche. ${ }^{20}$

Aproximações deste tipo são, melhor falando, uma exceção, pois a regra é o predomínio do sujeito que se indicou anteriormente e que conspira contra a percepção de uma sociedade mapuche diversa. Poucos autores avançam neste sentido, entre eles o citado Ramón Curivil, a cujo nome se deve acrescentar os de José Ancán e Margarita Calfio com suas pesquisas sobre os mapuches em Santiago. O trabalho de Ancán e Calfio (1999) é notável, pois chega a falar de "identidades mapuches", reconhecendo no mapuche urbano um componente diverso, o que chega a pluralizar aquilo que, em outros textos, aparece como uma identidade totalizadora. Encontramos outro exemplo novamente em Elicura Chihuailaf, que se coloca a si mesma como representante dessa diversidade, sem renunciar à existência de uma totalidade mapuche da que se sente parte.

Por isso, tenho a permanente impressão de que nunca me distanciei do meu mundo, porque sempre estou dialogando com ele, com sua memória, ainda na, às vezes, rara sensação de nostalgia. É aqui onde eu pertenço. Pertenço ao povo mapuche: sou uma expressão de sua diversidade. ${ }^{21}$

Há aqueles que declaram se opor às descrições caricaturescas que definem "de fora” o que é ou não é mapuche. É a reclamação de José Marimán, que critica o fundamentalismo de organizações como o Conselho de Todas as Terras e de todos aqueles discursos que se sustentam sobre a distinção de cosmovisões e a construção de um sujeito mapuche, essencialmente, ecológico e comunitário. No entanto, não é uma posição homologável a Chihuailaf, Curivil, Ancán e Calfio, porque se sustenta em argumentos que não se deslocam de quem critica, mas sim, ao contrário, aprofundam ainda mais na construção de um sujeito mapuche íntegro e não interferido pela modernidade. Assim, para José Marimán (1995), esse mapuche ecológico e comunitário é uma construção que responde às demandas que faz a sociedade moderna aos grupos indígenas. É, portanto, uma imagem alheia aos mapuches e a sua história. Nisto radicaria, segundo esse autor, o grande equívoco das organizações atuais, pois estariam demandando instituições análogas às da cultura dominante, convencidas de que têm seus referentes na cultura mapuche, como seria o caso da educação e da justiça. ${ }^{22}$

\section{A NAÇÃO MAPUCHE}

Os movimentos indígenas se autodenominam fazendo uso de uma nomenclatura distinta a de disciplinas como a Antropologia ou a Etnohistória, pois em lugar de etnias e grupos indígenas eles falam de povos ou nações para se identificar como coletivos

\footnotetext{
${ }^{20}$ CURIVIL. Algunas reflexiones socio antropológicas y filosóficas sobre el presente y el futuro del pueblo mapuche, p. 115.

${ }^{21}$ CHIHUAILAF. Recado confidencial a los chilenos, p. 25.

${ }^{22}$ MARIMÁN. La organización mapuche Aukiñ Wallmapu Ngulam.
} 
históricos anteriores à conformação dos Estados nacionais, mas que, ao mesmo tempo, são contemporâneos a eles. A palavra povo é atualmente a mais utilizada pelos movimentos e organizações indígenas, à que outorgam o significado político que lhe atribui o direito internacional, no qual é associada com território, autodenominação e soberania. Este é o sentido que perseguem as organizações e líderes da região, e é também o cerne da discussão em organismos internacionais como a ONU, que avança timidamente para este tipo de reconhecimento.

No entanto, esta coincidência entre as elites indígenas não significa que os conceitos de povo e nação remetam a formas de auto-representação similares ou a estratégias políticas idênticas. Pelo contrário, a diversidade que existe atrás da apropriação destas palavras enriquece o fenômeno da emergência indígena. ${ }^{23}$ Assim, pode-se constatar com alguns exemplos como o do Equador, país no qual se fala de "nacionalidades indígenas" desde finais dos anos setenta, aquelas que coexistiriam no interior do Estado equatoriano, definido, então, como um Estado multinacional. ${ }^{24} \mathrm{O}$ movimento indígena mexicano representa outra variante em que predomina o conceito de povo (povo zapoteca, povo tzeltal, huave, tarahumara, etc.), mas sem renunciar ao marco histórico e conceitual da nação mexicana, desde cedo entendida como um espaço de convivência entre os povos que a compõem. ${ }^{25} \mathrm{Em}$ ambas as situações, a definição clássica da nação moderna é alterada.

Neste contexto latino-americano, o movimento mapuche adquire relevância, pois creio que constitui outra tendência, cuja peculiaridade se encontra determinada por um contexto histórico particular: o processo de construção da nação chilena (oligarca, excludente e de consolidação rápida) e a incorporação tardia dos mapuches nela. $\mathrm{O}$ que predomina nos discursos das organizações atuais e na reflexão dos intelectuais (mais radicais que as primeiras, como desenvolverei posteriormente), é a identificação e autoafirmação de uma nação mapuche diametralmente distinta à nação chilena, cujo presente compartilhado seria uma situação anômala que deve ser revertida.

Os textos que integram nosso corpus são taxativos nesta representação da nação mapuche, cuja existência não é questionada em nenhum deles. Também coincidem em que se trata de uma continuidade histórica que é independente da identidade nacional mapuche que hoje começa a ter presença pública. Neste exercício de auto-afirmação, a discussão está centrada nos fundamentos históricos que permitem falar de uma nação mapuche e em sua possível reconstrução, deixando de lado a totalidade na qual se insere: o Estado chileno (não se avança além das acusações). Refiro-me com isso a que o debate sobre a forma e destino do Estado nação chileno não é um tema relevante, desinteresse que se deriva do conceito de nação que usam esses autores e sobre o qual Pablo Marimán lança algumas luzes.

Que foi o que destruíram os emergentes estados de Chile e Argentina? Descontinuaram a história de uma nação livre e independente. Para alguns, especialmente comprometidos com as responsabilidades e os destinos do Estado-nação, o termo nação é um conceito que

\footnotetext{
${ }^{23}$ BENGOA. La invención de las minorías.

${ }^{24}$ BARRERA. Acción colectiva y crisis política.

${ }^{25}$ ZAPATA. Discursos indianistas en México, 2003a, p. 297-327.
} 
não nos corresponde, pois associam (e assim ensinaram a minha geração nas escolas sob a ditadura militar) que nação e Estado são sinônimos, aspectos indissolúveis de uma mesma matéria. Porém ser nação é contar com crenças particulares, sistemas comunicacionais e simbólicos, histórias comuns, territórios, organização sócio-política, por último, sentir-se parte de algo comum que dá identidade própria diante de outros grupos humanos. ${ }^{26}$

Segundo Marimán, os fundamentos que permitem aos mapuches falar de uma nação distinta daquela em que se viram obrigados a viver seriam a existência de uma comunidade histórica anterior ao Estado chileno, cuja dinâmica cultural a levou a prescindir deste marco de organização política. Uma comunidade que possui um território, uma língua, uma identidade simbólica e própria, laços primordiais que a definem e que a levam a voltar o olhar para aquele passado onde existia a nação livre para tratar de reconstruir suas condições de existência.

O que temos aqui é um conceito de nação fundamentado em laços de coesão prémodernos, que se sustenta sobre o particularismo e a essência da cultura, derivando finalmente em uma concepção unitária (um povo, uma cultura, um território, uma nação). Isto determina essa conexão fraca com a nação chilena, distância que não é caprichosa, mas sim o produto de uma história na qual o Estado chileno operou com práticas de invasão e políticas excludentes que têm poucos similares na América. Esta história de separação se reflete na construção de uma identidade chilena de costas para a população indígena e na criação de uma ideologia para justificá-la. ${ }^{27}$

A produção escrita dos intelectuais mapuches explora esta distância e a aprofunda; não há nela lamentações pela sua exclusão da nação chilena, mas sim por ter que fazer parte dela. Assim se descreve na incipiente "história nacional mapuche", que aparece em fragmentos nesses textos, na qual se fala de conquista, invasão, colonização e ocupação (o território mapuche, ou wall mapu, seria, na atualidade, um território ocupado). Isto se assume como uma situação transitória, alimentando um projeto de reconstrução que nos seus aderentes mais entusiastas aparece como "liberação nacional", desejo que se expressa numa narrativa épica, que engrandece as particularidades da pátria, que fala de façanhas militares, heróis e, inclusive, do "exército nacional mapuche", como ocorre com a escrita de Marhiquewun, numa narração muito próxima das versões militares da identidade nacional.

O povo mapuche tem seus próprios heróis e heroínas, suas bandeiras e sua própria data de independência para celebrar, anterior à criação dos estados do Chile e da Argentina. Com efeito, Espanha reconheceu a independência da nação Mapuche no dia 6 de janeiro de 1641, no tratado de Killin ou Quillin, fixando-se como fronteira, entre a duas nações, o rio Bío-Bío.

$[\ldots]$

Não obstante, temos que reconhecer que nossa independência não foi um presente caído do céu, nem um mero acidente histórico, mas sim o esforço e a determinação do nosso glorioso povo Mapuche e suas forças armadas para não aceitar a escravidão e servidão que lhe ofereceram os colonialistas europeus e mais tarde seus descendentes.

$[\ldots]$

\footnotetext{
${ }^{26}$ MARIMÁN. Gobierno y territorio en la independencia mapuche, p. 14.

${ }^{27}$ PINTO. De la inclusión a la exclusión.
} 
Apesar do genocídio do final do século XIX, a lavagem cerebral para apagar a memória coletiva e a manipulação de nossos fatos históricos, não puderam nem poderão embaçar a memória e a façanha de nossos heróis e, hoje, apesar de nossa situação de povo oprimido, olhamos com orgulho e nobreza nosso passado glorioso de epopéias e vitórias, única na história universal, graças a este povo de heróis; podemos reclamar o posto que nos corresponde dentro das nações livres do mundo e notificá-los com firmeza e modéstia que fomos a primeira nação independente do continente Americano, e a última a ser "conquistada" militarmente. ${ }^{28}$

Não é freqüente encontrar este nível de patriotismo no leque de posições que aparece representado neste corpus, mas sim pode-se afirmar que predominam as definições integristas. Por exemplo, José Marimán sustenta que a nação mapuche pertence só aos mapuches, afirmação que condiciona o debate da questão indígena no Chile e o tipo de respaldo que possam receber da sociedade civil. Em referência a algumas manifestações de apoio ao movimento por parte de alguns intelectuais não indígenas, sustenta:

A rigor, a nação mapuche não é "nossa", no sentido de pertencimento aos chilenos. A nação mapuche pertence a si mesma e se encontra oprimida no interior do Chile. Disso os amigos do povo mapuche devem ter consciência clara, para transformar sua solidariedade em uma ajuda certa ao processo de libertação nacional de um povo oprimido e colonizado. Processo que parece estar tomando a forma de uma demanda por autonomia ou autodeterminação interna, no caso mapuche. ${ }^{29}$

Esta demanda por autonomia é central no projeto de liberação nacional e, talvez, a principal contribuição dos intelectuais mapuches seja fundamentá-la a partir das distintas áreas de conhecimento em que hoje se desempenham, mas, apesar de necessária, é um dos temas mais nebulosos desta produção escrita. As definições são vagas e se avança muito pouco em propostas de implementação. No entanto, o tom nacionalista desta escrita faz pensar que a fórmula geral de um sistema de autonomia como certas prerrogativas no interior do Estado chileno não seria suficiente. Um nó problemático, em nossa opinião, é que se apreciam desajustes entre estas propostas de autonomia e o conceito de nação mapuche que, paralelamente, se afirma. É assim como encontramos textos nos quais a narrativa nacionalista mais acirrada parece se moderar e seguir tendências internacionais sobre a matéria; de fato, se está pensando em modelos políticos de multiculturalismo tais como Espanha, Canadá, Austrália, Inglaterra, Nova Zelândia e, inclusive, Estados Unidos (José Marimán e R. Marhiquewun, entre outros), tipos de organização que, desde cedo, são distintos ao Estado unitário que predomina na América Latina, mas que estão longe da linguagem radical que usam esses intelectuais quando se pronunciam sobre a distância que separa a nação mapuche da nação chilena. Do outro lado, temos uma posição que se refere à autonomia em termos de soberania, desconsiderando o papel do Estado, pois se trataria de um problema mapuche que não deve ser submetido a negociação. Assim o pensa Marcos Valdés (Wekull), para quem a autonomia não pode ser reduzida a uma demanda dirigida ao Estado, mas sim deve ser proposta como uma construção de poder (o que ele chama de empoderamento) capaz de enfrentar as novas estratégias assimilacionistas. ${ }^{30}$

\footnotetext{
${ }^{28}$ MARHIKEWUN. Independencia de Chile versus dependencia mapuche.

${ }^{29}$ MARIMÁN. El nacionalismo asimilacionista chileno y su percepción de la nación mapuche y sus luchas.

${ }^{30}$ VALDÉS; CURÍN. Entre la integración y la autonomía.
} 
Este sentimento nacionalista é o marco que permite entender a eleição e o uso recorrente da palavra diáspora, utilizada para interpretar a migração para os centros urbanos. Assim, diáspora - conceito alcunhado por Pedro Marimán no começo dos anos noventa - refere-se a um momento doloroso na história da nação mapuche: a saída do território histórico, por múltiplos fatores econômicos e sociais, produto de sua posição subordinada no interior da nação chilena. Porém, mais que isso, é uma palavra com a força necessária para representar um povo desagregado, que deambula por território alheio, daí que alguns se atrevam a estabelecer o paralelo com Israel, símbolo dos povos errantes. ${ }^{31}$ Os múltiplos fenômenos sociais e culturais que representa um movimento migratório desta envergadura são relegados a um segundo plano diante do significado que dito movimento tem para a nação mapuche: um "desligamento populacional", nas palavras de Pablo Marimán (1996).

Apesar de compartilhar as características centrais desta identidade nacional mapuche, Arauco Chihuailaf parece propor-se outros problemas, empurrando sua reflexão para essa totalidade na qual a nação mapuche se encontra inserida: o Estado chileno.

A idéia de "país unitário", sustentado pelas elites, omitiu mais que secularmente a pluralidade de culturas e de identidades. Hoje, caberia se interrogar seriamente sobre a viabilidade de tal concepção da nação, não como questionamento da integridade do país, mas sim como busca de um projeto coletivo que, se assentando na diversidade de realidades, permita ao "Chile que vem" fundar-se na participação de todos seus componentes a partir do que lhe é próprio. Tanto mais quanto se reconhece que "uma sociedade pluricultural e pluriétnica não atenta contra a unidade nacional, nem nos seus aspectos políticos, nem sociais". ${ }^{32}$

Esta crítica de Arauco Chihuailaf ao caráter unitário do Estado chileno tem como pano de fundo um conceito de nação que não está fundado no particularismo como razão de ser e de destino, perspectiva que representa um desafio tanto para aqueles que postulam definições integristas da nação chilena quanto para os intelectuais e organizações mapuches cujas posições nacionalistas se sustentam sobre a absolutização da diferença. Porém, além destas exceções, o que predomina é a distinção taxativa entre nação mapuche e nação chilena. Adiantando-me às conclusões deste trabalho, o que considero problemático é que não só se identifica um passado diverso, mas sim um futuro igualmente separado, pois não se vislumbra nestas reflexões um horizonte compartilhado; e não estou falando de uma integração de velho cunho, mas sim de algo mais complexo: de um espaço de convergência. Não obstante, entendo a formulação de propostas nacionalistas entre esses intelectuais e algumas organizações como o elo mais contemporâneo de um conflito que funda suas raízes na conquista espanhola, o que recrudesceu na década de 1880 com a campanha militar que empreendeu o Estado chileno na Araucania, recordada como a etapa mais violenta desta relação desigual, de acordo com os textos que aqui foram analisados. Assim, a imaginação ou recomposição da comunidade e a reivindicação daquele passado negado pelo Estado nacional por meio de instituições como a escola e o quartel aparecem como uma etapa relevante na

\footnotetext{
${ }^{31}$ ANCÁN; CALFIO. El retorno al País Mapuche, p. 54.

${ }^{32}$ CHIHUAILAF. Condena y animosidad de clase hacia la lucha mapuche por la tierra.
} 
resistência para uma hegemonia que tem sua gênese no fato colonial, como o recordou o crítico palestino Edward W. Said, reconhecimento que não o impediu de advertir sobre os riscos do nativismo e sua negação de pluralidade humana. ${ }^{33}$ Como se verá na próxima parte, o projeto de reconstrução nacional mapuche, na voz desses intelectuais, tem a ver com a recuperação dos componentes fundamentais: população e território.

\section{TERRITÓRIO: O "PAís MAPUCHE"}

A questão da terra e a memória do despojo são uma continuidade no Movimento Mapuche ao longo do século XX, mas na atualidade a formulação deste problema se deslocou junto com os discursos das organizações. Sua relação com o conceito de nação o politizou além de possíveis recuperações, sendo a palavra território o centro neurálgico de um nacionalismo mapuche que alcança seu ponto mais alto na escrita de seus intelectuais. Nas palavras de Marcos Valdés (Wekull), a memória e a identidade mapuche só têm sentido nesta territorialidade, que se erige como um dos principais laços de coesão para uma nação segmentada no âmbito político: "Los mapuches compartilhamos uma memória histórica comum e também uma identidade cultural comum, mas esses elementos têm sentido se, e somente se, são interpretados territorialmente [...]"34

O deslocamento da demanda de "terras" a "território" é indicador desta mudança conceitual e política, pois o território arrebatado constitui, para esses intelectuais, a base material sobre a qual se recria a nação mapuche: sua cultura, ritualidade, organização social, além da dimensão econômica que possui. É um discurso que se radicalizou durante o transcurso dos anos noventa, ampliando a distância com o tipo de reconhecimento que contempla a Lei Indígena (1993) e que, em algum momento, respaldaram, pois se trata de um instrumento legal que, ao falar de "terras indígenas", reduz o tema à questão econômica e a organização mapuche aos limites da comunidade, muito distante do povo e a nação que os líderes, as organizações e, sobretudo, os intelectuais reivindicam.

Para estes últimos, o território é o pilar de um projeto de reconstrução nacional com o qual alcançam um grau de radicalidade maior ao das organizações. ${ }^{35}$ Essas são acusadas de uma leitura equivocada do tema, cuja conseqüência seria o desenho de estratégias igualmente erradas. Para os intelectuais, a análise restringida das organizações teria redundado numa demanda insuficiente, limitada só às terras reducionais, aquelas que o Estado chileno distribuiu, entre 1884 e 1927, com sua política de radicação. ${ }^{36}$

\footnotetext{
${ }^{33}$ Said postula que a nação é um passo necessário, mas, ao mesmo tempo, insuficiente para a concretização de um projeto que busca construir um novo universalismo e um novo humanismo, capaz de reconhecer a heterogeneidade e as diferenças, utopia que resgatou de Fanon em sua última etapa (a de Os condenados da terra) que animou seu projeto de buscar formas de pensar que se distanciam da outridade reducionista e caricaturesca. (SAID. Cultura e imperialismo, cap. 3, p. 299-434).

${ }^{34}$ VALDÉS (WEKULL); CURÍN. A propósito de errores ancestrales y desaciertos contemporáneos.

${ }^{35}$ Refiro-me àquelas que usam uma posição confrontacional com o Estado chileno, como o Conselho de Todas as Terras, Identidade Lafquenche e a Coordenadoría Arauco Malleco, cujos discursos também giram em torno da nação mapuche e a autonomia.
}

${ }^{36}$ PINTO. De la inclusión a la exclusión. 
[...] é bastante notável fazer ver um dado freqüentemente esquivado por grande parte dos ativistas Mapuche contemporâneos, integrantes do movimento "formal" que mencionávamos: as atuais "comunidades Mapuche" (ou melhor, o que sobrou delas) em seus limites geográficos, tal qual afirmamos acima, não são outra coisa que os resíduos do antigo País Mapuche. Então, as atuais demandas, em sua plena legitimidade, são só inaugurais na hora de começar sequer a nos interrogar sobre a idéia de um Território Mapuche possível. ${ }^{37}$

$\mathrm{Na}$ perspectiva desses intelectuais, o uso de uma visão histórica que considere aquela época em que a nação mapuche era livre conduz inevitavelmente à identificação de um território mais amplo e contínuo que eles denominam território histórico. Portanto, reclamar unicamente as terras reducionais significaria legitimar um sistema de domínio e aceitar o decepamento da nação mapuche.

Este território histórico também é sinalizado com outro conceito recorrente: o "país mapuche", cujos limites geográficos não são bem precisos. José Ancán e Margarita Calfio são os autores que mais aprofundam no problema de sua superfície, respaldando suas afirmações com as crônicas de viajantes do século XIX, nas quais se fazia menção a um vasto território indígena:

Sem prejuízo de que se pudesse entrar numa ampla, e por demais necessária, polêmica sobre as delimitações e configuração mais ou menos exata do antigo território Mapuche, dos textos citados, podemos, por enquanto, extrair algumas observações importantes para nossos fins específicos. Fazendo abstração do dado chave do caráter binacional daquele espaço, no que diz respeito à Araucania atualmente chilena, no momento de ser ocupada militarmente, panoramicamente compreendia, de norte a sul, as terras situadas entre as atuais províncias de Bío Bío e Llanquihue. ${ }^{38}$

O problema atual para o movimento mapuche consiste em que este território não só foi reduzido e alienado, mas sim "ocupado", um país invadido, nas palavras de Marhiquewun, interpretação que contém a possibilidade de sua recuperação. Ancán e Calfio vão além: o país mapuche tem fundamento histórico e deve estar no horizonte imediato das mobilizações.

A associação entre nação e país mapuche, ou seja, entre a comunidade histórica e seu território, é indissolúvel. No caso específico de José Ancán, Margarita Calfio, José Marimán e R. Marhiquewun, esta associação se propõe como um tema que deve ser debatido pelas organizações, cuja obrigação é tomar conta do problema nacional que envolve. A partir desta análise, estima-se que a reivindicação dos 500.000 hectares dos Títulos de Mercês só podem constituir um ponto de partida na luta pelo território.

A migração é um dos maiores obstáculos para a concretização deste projeto. Aqui é onde o conceito de diáspora adquire maior significado, pois não só se refere ao fato da fuga obrigatória, mas sim à possibilidade de retorno. Isto demonstra a consciência que existe em torno da variável demográfica como o eixo fundamental de qualquer sistema de autonomia, por tímida que seja sua proposta e mais ainda se se atende ao sentido nacional com que aparece nestes textos. Fala-se então de "repovoar" o país mapuche.

\footnotetext{
${ }^{37}$ ANCÁN \& CALFIO. El retorno al País Mapuche, p. 59.

${ }^{38}$ A esta descrição teria que acrescentar territórios que atualmente pertencem à Argentina.
} 
Aqueles que se pronunciam mais abertamente sobre este retorno são novamente Ancán e Calfio, em cujo trabalho ficam mais claros os alcances deste projeto. Para eles, o problema não é a vida urbana em si, mas o fato de ter que viver fora dos limites do país mapuche, entendido como o lugar natural de pertencimento. Uma análise que outorga distinto status à migração urbana, pois não seria a mesma coisa viver em Temuco que viver em Santiago (de fato, postula-se Temuco como a capital do país mapuche), por isso se torna problemática a migração para Santiago e se explica o peso que teve este destino no movimento migratório.

Porém, o "país mapuche" também é um espaço escuro nestes textos (não todos o refletem com a profundidade de Ancán e Calfio), pois não se repara nas possíveis conseqüências ou em como eles visualizam a implementação deste projeto: está-se falando de um território habitado só por mapuches? Se não é assim, está-se pensando em algum tipo de convivência? De que tipo? O que aconteceria com a organização municipal? José Marimán se pronuncia sobre percepções deste tipo, advertindo que em nenhum caso se está pretendendo a limpeza étnica, mas sim o novo pluralismo, ${ }^{39}$ intenção que não resolve todas as dúvidas que desperta uma proposta deste tipo e que são de ordem tanto prática quanto política.

\section{A}

\section{RESU MEN}

Este artículo tiene por objetivo dar cuenta de un nuevo sujeto indígena, cuyo surgimiento lo podemos ubicar en la segunda mitad del siglo XX. Me refiero al intelectual indígena contemporáneo, que entendemos como aquel que fue formado en instituciones de educación superior y que construye discursos y representaciones desde una disciplina del conocimiento (historia, sociología, literatura, antropología, entre otras). Se abordará el caso particular de los intelectuales mapuches en la década de los noventa, desde una perspectiva de análisis que los considera en tanto autores y como actores de contornos propios al interior de lo que en la actualidad se conoce como Movimiento Mapuche. Por este motivo, el corpus de documentos se constituye principalmente de ensayos, artículos y libros elaborados por estos intelectuales, en los que se despliegan argumentos y reflexiones sobre el colectivo cultural que representan a través de la escritura. Las conclusiones de esta aproximación se han organizado en torno a tres ejes que se erigen como los pilares de esta producción: identidad, nación y territorio.

\section{PALABRAS CLAVE}

Intelectual indígena. Identidad. Nación. Texto.

\footnotetext{
${ }^{39}$ MARIMÁN. El protagonismo político del nuevo director de CONADI.
} 


\section{REFERÊNCIAS}

ANDERSON, Benedict. Comunidades imaginadas: Reflexiones sobre el origen y la difusión del nacionalismo. México, D.F.: Fondo de Cultura Económica, 1991 [1983].

ANCÁN, José; CALFIO, Margarita. El retorno al País Mapuche: reflexiones preliminares para una utopía por construir. Liwen, Temuco, Chile, n. 5, p. 43-77, 1999.

ANCÁN, José. Rostros y voces tras las máscaras y los enmascaramientos: los mapuche urbanos. In: CONGRESO CHILENO DE ANTROPOLOGÍA, 2, 1996. Actas... Santiago: Colegio de Antropólogos de Chile, 1997. v. 1, p. 307-314.

ANTILlANCA, Ariel; CUMINAO, Clorinda; LONCÓN, César. Escritos mapuches: (1910-1999). Santiago de Chile: Consejo Nacional del Libro y la Cultura; Associación Mapuche Xawun Ruka, 2000.

BARRERA, Augusto. Acción colectiva y crisis política. El movimiento indígena ecuatoriano en la década de los 90. Quito: Abya Yala, 2001.

BELLO, Álvaro. Intelectuales indígenas y universidad en Chile: conocimiento, diferencia y poder entre los mapuches. In: HENRY, Robert Austin (compilador). Intelectuales y educación superior en Chile: de la independencia a la democracia transicional 1810-2001. Santiago: CESOC, 2003. p. 67-99.

BENGOA, José. La invención de las minorías: las identidades étnicas en un mundo globalizado. Revista de la Academia, Universidad Academia de Humanismo Cristiano, n. 7, p. 9-37, 2002.

BENGOA, José. La emergencia indígena en América Latina. Santiago: Fondo de Cultura Económica, 2000.

BOURDIEU, Pierre. Intelectuales, política y poder. Buenos Aires: Eudeba, 2000 [1999].

CALBUCURA, Jorge. Entrevista a la revista Rocinante. Rocinante, año 3, n. 15, ene. 2000.

CALBUCURA, Jorge. Entrevista a El mercurio electrónico. El mercurio electrónico, Santiago de Chile, 19 mar. 2000.

CALBUCURA, Jorge. Antes de antes, siempre hubo un antes. Centro de Documentación Mapuche Nuke Mapu, 12 oct. 2000.

CALBUCURA, Jorge. Araucanía dilema ancestral. Rocinante, Centro de Documentación Mapuche Nuke Mapu, v. 3, n. 24, 2000.

CALBUCURA, Jorge. La cuestión indígena y el dilema del doloroso desarraigo de la clase política chilena. Rocinante, Centro de Documentación Mapuche Nuke Mapu, v. 4, n. 30, abr. 2001.

CALBUCURA, Jorge; MARIQUEO, Reynaldo. La Nación Mapuche. Centro de Documentación Mapuche Nuke Mapu, set. 2002.

CAÑULEF, Eliseo; DÍAZ COLIÑIR, María. Interculturalidad y los derechos indígenas. In: INFANTE, S. P. (Comp.). Pueblo mapuche: desarrollo y autogestión. Análisis y perspectivas en una sociedad pluricultural. Concepción: Centro Integral de Desarrollo Comunitario; Ediciones Escaparate, 2000. p. 133-145.

CARRASCO, Hugo. El discurso público mapuche: procedimientos textuales identitarios. Universum, Universidad de Talca, n. 17, p. 11-27, 2002. 
CESAIRE, Aimè. Discurso sobre el colonialismo. In: ZEA, Leopoldo (Comp.). Fuentes de la cultura latinoamericana. México: Fondo de Cultura Económica, 1993 [1950]. v. 2, p. 307-324.

CHIHUAILAF, Arauco. La ausencia de Chile en "Chile: el país que viene". Centro de Documentación Mapuche Nuke Mapu, nov. 2000.

CHIHUAILAF, Arauco. Movilizaciones mapuches e ideología neoliberal. Centro de Documentación Mapuche Nuke Mapu, nov. 2000.

CHIHUAILAF, Arauco. Condena y animosidad de clase hacia la lucha mapuche por la tierra. Centro de Documentación Mapuche Nuke Mapu, 30 mar. 2002.

CHIHUAILAF, Elicura. Recado confidencial a los chilenos. Santiago: LOM, 1999.

COLOM, Francisco. Razones de identidad: pluralismo cultural e integración política, Barcelona: Anthropos, 1998.

CONTRERAS PAINEMAL, Carlos. La oralidad y la escritura en la sociedad mapuche. In: PAINEMAL, Carlos Contreras (Ed.). Actas del Primer Congreso Internacional de Historia Mapuche. Siegen, Alemania: Eigenverlag, 2003. p. 3-11.

CURIVIL, Ramón. Algunas reflexiones socio antropológicas y filosóficas sobre el presente y el futuro del pueblo mapuche. In: INFANTE, S. P. (Comp.). Pueblo mapuche: desarrollo y autogestión. Análisis y perspectivas en una sociedad pluricultural. Concepción: Ediciones Escaparate, 2000. p. 107-115.

DEVÉS VALDÉS, Eduardo. El pensamiento latinoamericano en el siglo XX. Entre la modernización y la identidad. Santiago de Chile: Editorial Biblos; Centro de Investigaciones Barros Arana, 2000, 2003 y 2004. v. 1, 2 y 3 respectivamente.

DÍAZ POLANCO, Héctor. Autonomía regional. La autodeterminación de los pueblos indios. México: Siglo XXI, 1999 [1991].

FANON, Frantz. Los condenados de la tierra. México: Fondo de Cultura Económica, 1963 [1961].

FOERSTER, Rolf. Sociedad mapuche y sociedad chilena: la deuda histórica. Polis, Revista de la Universidad Bolivariana, v. 1, n. 2, 2001. Versión electrónica.

FOERSTER, Rolf; VERGARA, Jorge I. Algunas transformaciones de la política mapuche en la década de los noventa. Anales de la Universidad de Chile, Sexta Serie, n. 13, ago. 2001. Versión electrónica.

FOERSTER, Rolf; VERGARA, Jorge I. Etnia y nación en la lucha por el reconocimiento. Los mapuches en la sociedad chilena. In: GUNDERMANN, Hans; FOERSTER, Rolf; VERGARA, Jorge I. Mapuches y aymaras: el debate en torno al reconocimiento y los derechos ciudadanos. Santiago: Universidad de Chile, Facultad de Ciencias Sociales; RIL Editores, 2003. p. 105-177. (Serie de Investigación).

GARCÍA CANCLINI, Néstor. La globalización imaginada. Buenos Aires: Paidós, 2001 [1999]. GRUZINSKI, Serge. El pensamiento mestizo. Barcelona: Paidós, 2000 [1999].

GUTIÉRREZ CHONG, Natividad. Mitos nacionalistas e identidades étnicas: los intelectuales indígenas y el Estado mexicano. México, D.F.: Consejo Nacional para la Cultura y las Artes, Instituto de Investigaciones Sociales, Editorial Plaza y Valdés, 2001 [1999]. 
KOTOV, Rita; VERGARA, Jorge. La identidad mapuche en la perspectiva de los intelectuales indígenas. In: CONGRESO CHILENO DE ANTROPOLOGÍA, 2. Actas... Santiago: Colegio de Antropólogos de Chile, 1997. v. 1, p. 452-461.

LAVANCHY, Javier. Conflicto y propuestas de autonomía mapuche. Santiago: Centro de Documentación Mapuche Nuke Mapu, 1999.

LAVANCHY, Javier. Perspectivas para la comprensión del conflicto mapuche. Santiago: Fundación Rehue, 1999. Publicación electrónica.

MARHIKEWUN, R. Mapuches acusados de antipatriotas por chilenos nacionalistas y racistas. Bristol: Centro de Documentación Mapuche Nuke Mapu, 30 set. 1998.

MARHIKEWUN, R. Gobierno chileno endurece su política antimapuche. Bristol: Centro de Documentación Mapuche Nuke Mapu, 13 de oct. 1998.

MARHIKEWUN, R. Independencia mapuche suspendida. Bristol: Centro de Documentación Mapuche Nuke Mapu, 8 oct. 2000.

MARHIKEWUN, R. Independencia de Chile versus dependencia mapuche. Bristol: Centro de Documentación Mapuche Nuke Mapu, 10 oct. 2000.

MARILEO LEFIO, Armando. Mundo mapuche. In: PAINEMAL, Carlos Contreras (Ed.). Actas del Primer Congreso Internacional de Historia Mapuche. Siegen, Alemania: Eigenverlag, 2003. p. 27-44.

MARIMÁN, José A. Transición democrática en Chile. ¿Nuevo ciclo reivindicativo mapuche? CEDM Liwen, Centro de Documentación Mapuche Nuke Mapu, ene. 1994. MARIMÁN, José A. La organización mapuche Aukiñ Wallmapu Ngulam. Denver, USA: Centro de Documentación Mapuche Nuke Mapu, abr. 1995.

MARIMÁN, José A. Movimiento mapuche y propuestas de autonomía en la década post dictadura. Denver, USA: Centro de Documentación Mapuche Nuke Mapu, abr. 1997.

MARIMÁN, José A. El nacionalismo asimilacionista chileno y su percepción de la nación mapuche y sus luchas. Denver, USA: Centro de Documentación Mapuche Nuke Mapu, jun. 2000. MARIMÁN, José A. El protagonismo político del nuevo director de CONADI. Denver, USA: Centro de Documentación Mapuche Ñuke Mapu, nov. 2002.

MARIMÁN, Pablo. Elementos de historia mapuche. Centro de Documentación Mapuche Ñuke Mapu, 1996.

MARIMÁN, Pablo. Gobierno y territorio en la independencia mapuche. In: PAINEMAL, Carlos Contreras (Ed.). Actas del Primer Congreso Internacional de Historia Mapuche. Siegen, Alemania: Eigenverlag, 2003. p. 12-26.

MARIMÁN, Pedro; HAUGHNEY, Diane. Población mapuche: cifras y criterios. Centro de Documentación Mapuche Nuke Mapu, 1993.

MILLALEO, Salvador. Ser/no ser, mapuche o mestizo. Centro de Documentación Mapuche Nuke Mapu, 2002.

MILLAMAN, Rosamel. Nacionalismo y eurocentrismo como fuerzas antagónicas y uniformes de Estado para el desarrollo mapuche. In: INFANTE, S. P. (Comp.). Pueblo mapuche: desarrollo y autogestión. Análisis y perspectivas en una sociedad pluricultural. Concepción: Ediciones Escaparate, 2000. p. 37-42. 
MONTECINO, Sonia; FOERSTER, Rolf. Organizaciones, líderes y contiendas mapuches (1900-1970), Santiago: Centro de Estudios de la Mujer, 1988.

PINTO, Jorge. De la inclusión a la exclusión: la formación del estado, la nación y el pueblo mapuche. Santiago: Instituto de Estudios Avanzados, Universidad de Santiago de Chile, 2000. (Colección IDEA).

RENAN, Ernest. ¿Qué es una nación? In: BRAVO, Álvaro Fernández (Comp.). La invención de la nación: lecturas de la identidad de Herder a Homi Bhabha. Buenos Aires: Ediciones Manantial, 2000 [1882]. p. 53-66.

ROJO, Grínor. Diez tesis sobre la crítica. Santiago: LOM, 2001.

ROJO, Grínor. Globalización e identidades nacionales: precisando conceptos. 2004. Inédito.

ROJO, Grínor; SALOMONE, Alicia; ZAPATA, Claudia. Postcolonialidad y nación. Santiago: LOM, 2003.

SAID, Edward W. Cultura e imperialismo. Barcelona: Anagrama, 1996 [1993].

SMITH, Sara. Multiculturalismo y nación: historia del multiculturalismo canadiense para compararlo al modelo Estado nación chileno. 2003. Inédito.

SPIVAK, Gayatri. ¿Puede hablar el sujeto subalterno? Orbis Tertius, Buenos Aires, v. 3, n. 6, p. 175-235, 1998.

STAVENHAGEN, Rodolfo. Los conflictos étnicos y sus repercusiones en la sociedad internacional. Disponível em: <www.cholonautas.edu.pe>. Acesso em: 1991.

VALDÉS (WEKULL), Marcos; CURÍN, Eduardo. A los intelectuales; o, de cómo resulta necesario repensar la cuestión mapuche. In: INFANTE, S. P. (Comp.). Pueblo mapuche: desarrollo y autogestión. Análisis y perspectivas en una sociedad pluricultural. Concepción: Ediciones Escaparate, 2000. p. 155-176.

VALDÉS (WEKULL), Marcos; CURÍN, Eduardo. A propósito de errores ancestrales y desaciertos contemporáneos: una respuesta posible a Villalobos. Net Mapu. Disponível em: <www.mapuche.cl>. Acesso em: jun. 2000.

VALDÉS (WEKULL), Marcos; CURÍN, Eduardo. Entre la integración y la autonomía: la mirada intelectual del conflicto mapuche. Disponível em: <www.mapuche.cl>. Acesso em: 2000.

VARESE, Stefano. ¿Estrategia étnica o estrategia de clase? In: . Indianidad y descolonización en América Latina. Documentos de la Segunda Reunión de Barbados. México, D. F.: Editorial Nueva Imagen, 1979. p. 357-372. (Serie Interétnica).

VERGARA, Jorge Iván. ¿La voz de los sin voz? Análisis crítico de la producción e interpretación de testimonios en las ciencias sociales. Estudios Atacameños, San Pedro de Atacama, n. 17, p. 7-23, 1999.

ZAPATA, Claudia. Discursos indianistas en México. Hacia una nueva representación del Estado nacional, 1974-2000. In: CASTILlO, A. et al. Nación, Estado y cultura en América Latina. Santiago: Ediciones Facultad de Filosofía y Humanidades, Universidad de Chile, 2003a. p. 297-327. (Serie Estudios).

ZAPATA, Claudia. El zapatismo en México, ipostmodernidad y postcolonialidad en América Latina? Armas y Letras, Monterrey, n. 46, p. 72-81, 2004. 
ZAPATA, Claudia. Origen y función de los intelectuales indígenas. Cuadernos Interculturales, Universidad de Valparaíso, v. 3, n. 4, p. 65-87, abr. 2005.

ZAPATA, Claudia. Los intelectuales indígenas y la representación. Una aproximación a la escritura de José Ancán Jara y Silvia Rivera Cusicanqui. Revista de Historia Indígena, Departamento de Ciencias Históricas, Universidad de Chile. En prensa.

Tradução de Marcos Antônio Alexandre 